\title{
Pre-Peak Deformation and Damage Features of Sandstone under Cyclic Loading
}

\author{
Chengjie LI, Peijie LOU, Shuling LIANG, Mingming FENG, Bin PAN
}

\begin{abstract}
In this paper, several sandstone specimens are prepared and subjected to uniaxial compression and cyclic loading. For each specimen, the loading segment of the stress-strain curve was fitted, and the peak slope of this segment was taken as the elastic modulus of the specimen in that cycle. It is learned that, under cyclic loading, the elastic modulus of each specimen increased with the growing number of load cycles, and tended to be stable; meanwhile, strain hardening was observed on all specimens. Moreover, the specimens are similar in corresponding stress, although varied in corresponding strain. In the same cycle, the tangent modulus of the loading phase was smaller than that of the unloading phase under the same stress. Finally, the damage variables of sandstone specimens under cyclic loading were defined from the angle of energy, revealing that the damage variables had logarithmic growth with the load cycles in the later stage.
\end{abstract}

Keywords: accumulation energy; damage variable; pre-peak phase; strain hardening

\section{INTRODUCTION}

Recent years have seen a boom in the construction of underground works like mountain tunnels, subsea tunnels, metros and mines. These underground works have changed the original geo-stress state, and imposed cyclic loads on the surrounding rock. Therefore, many scholars have explored the deformation and damage features of rocks under cyclic loading [1-6].

Cyclic loading / unloading tests have shown that the rock specimen will undergo strain hardening or strain softening to different degrees, depending on the rock type, load magnitude, number of load cycles or unloading time. This phenomenon can be described by the variation in elastic modulus. In uniaxial loading tests, the elastic modulus is often measured by the slope of the stress-strain curve in the loading phase or that of the secant to the stressstrain curve in the unloading phase [7]. Some scholars have obtained the elastic modulus through theoretical derivation [8], and verified the result through experiments and field applications [9-10]. For instance, Yan, [11] and Xia, [12] conducted a freeze-thaw cycle test and a cyclic uniaxial stress-temperature test on rocks, respectively, aiming to disclose the change law of elastic modulus. Through cyclic loading tests, Ge, [13] and Wang, [14] discovered that the rock is damaged in each cycle, whether it is hardened or softened under the strain, and will suffer from fatigue failure when the load level or load cycle reaches a certain threshold.

The variable that characterizes rock damages is called the damage variable. Drawing on the hypothesis of strain equivalence, Lemaitre et al. [15] defined the rock damage with the difference in elastic modulus between the intact rock and the damaged rock:

$$
D=1-\frac{E_{\mathrm{s}}}{E_{0}}
$$

where, $E_{0}$ and $E_{\mathrm{s}}$ are the elastic moduli of intact and damaged rocks, respectively. $E_{0}$ and $E_{\mathrm{s}}$ are the secant modulus of the stress-strain relationship curve.

However, Xie et al. [16, 17] argued that this formula only applies to the description of elastic / brittle damages rather than that of elastic-plastic damages, and proposed a new method to identify elastic-plastic damages, which considers the effects of plastic deformation and damages.

By this method, Liu et al. [18-19] examined the test methods for the damage variable of rocks with obvious vicious deformation, and concluded that the damage features can be accurately reflected by low-frequency cyclic loading / unloading test, which has a highly timesensitive elastic modulus. Zhou et al. [20] computed the damage variable based on the stress-strain curve, and obtained results that agree with the data of acoustic emission testing. Xu et al. [21] calculated the stress index of rock by Norton' s empirical formula and the seven-point method, and determined the damage variables at different time points, in the light of the theory of damage mechanics and the exponential relationship between stable and accelerated creeps. This relationship was proposed by Norton.

Fan et al. [22] compared several definitions of effective modulus method, and recommended to measure the damage variable of rock by the secant modulus method with $\eta$ - coefficient. Zhao et al. [23] redefined the damage variable as a relative concept, confirmed the linear positive relationship between the damage variable and plastic strain, and quantified the critical energy loss that leads to fatigue failure of rock. In fact, rock failure is essentially the loss of stability induced by energy evolution [24]. The mechanism of energy evolution during rock deformation and failure can be found in Reference [25].

In this paper, several sandstone specimens were subjected to uniaxial compression and cyclic loading, respectively. For each specimen, the loading segment of the stress-strain curve was fitted, and the peak tangent modulus was taken as the elastic modulus of the specimen. Based on the stress-strain curves, the damage variables of the sandstone specimens under cyclic loading were defined from the angle of energy. In addition, the damage variable of rock under cyclic loading was also defined from the perspective of energy. The research findings shed new light on the pre-deformation and damage features of sandstone specimens under cyclic loading.

\section{MATERIALS AND METHODS}

Before the tests, sandstone blocks were collected from the same coalface at the depth of $-848 \mathrm{~m}$ in Gubei 
Coalmine, Huainan, eastern China' s Anhui Province. These blocks were transported to our lab and processed into $\varnothing 50 \times 100 \mathrm{~mm}$ standard specimens, through coring, cutting and polishing. Then, the surface moisture of the specimens was removed by filter papers, and assigned different numbers. Taking specimen 3-1 for example, the number 3 means the specimen was taken from the third sandstone block, and the number 1 is randomly assigned. After that, some specimens with obvious defects were discarded, while the qualified specimens were dried naturally, and stored in airtight containers for further use.

Our tests were conducted on the RMT-150B rock mechanics test system of Anhui University of Science and Technology. Before the tests, the mean density of all specimens was measured to be $2,41 \mathrm{~g} / \mathrm{cm}^{3}$. Next, three specimens were selected for the uniaxial compressive strength test. The results show that the mean uniaxial compressive strength of sandstone was $64,53 \mathrm{MPa}$. After that, 5 specimens were selected for the cyclic loading test. Firstly, the load was applied in the form of a sine wave (frequency: 0,02 Hz; amplitude: $80 \mathrm{kN}$ ): in each load cycle, the axial load was gradually increased from zero to $80 \mathrm{kN}$ and then gradually unloaded to zero. After five load cycles, the load was increased linearly until the specimen failed.

\section{RESULTS ANALYSIS}

\subsection{Pre-Peak Deformation Features}

The stress-strain curves of a specimen under uniaxial compression and cyclic load are shown in Fig. 1 and Fig.
2 , respectively. The specimen deformation under uniaxial compression can be divided into four phases [7]. Only the pre-peak phase is discussed in this paper.

As shown in Fig. 1, the pre-peak segment (AD) of the stress-strain curve was shaped like a long and narrow $\mathrm{S}$. Normally, the elastic modulus of the specimen can be measured by the slope of the approximately linear segment (BC). Because this segment is not strictly linear, an interval of the slope was obtained rather than a specific value.

To solve the problem, the AD segment was subjected to polynomial fitting. The $R$-squared $\left(R^{2}\right)$ was above 0,9999 . The slope of the fitted curve was found to increase first and then decrease. Therefore, the tangent modulus must have a peak value. Here, the peak tangent modulus is taken as the elastic modulus of the specimen.

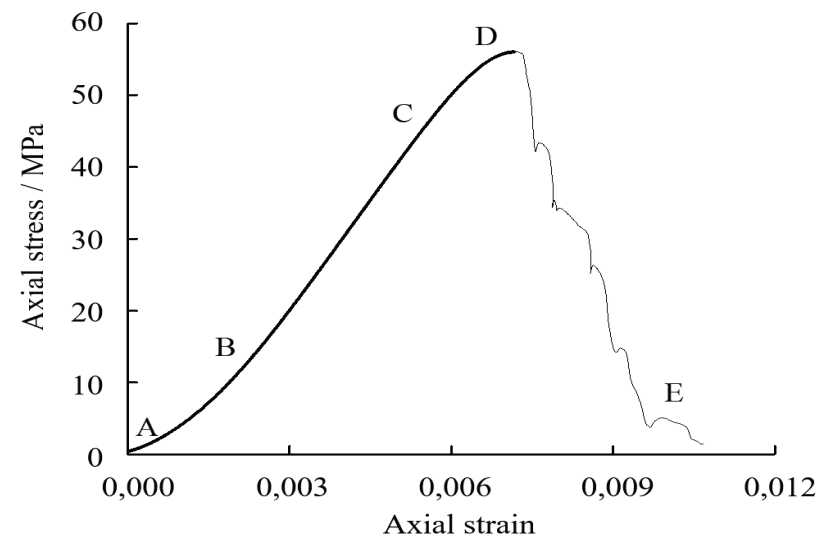

Figure 1 Stress-strain curve under uniaxial compression

Table 1 Plastic strains, elastic moduli, and corresponding stresses and strains of each

\begin{tabular}{|c|c|c|c|c|c|c|c|}
\hline \multirow[b]{2}{*}{ Specimen } & \multirow[b]{2}{*}{ Cycle } & \multicolumn{3}{|c|}{ Loading phase } & \multicolumn{3}{|c|}{ Unloading section } \\
\hline & & $\begin{array}{l}\text { Corresponding } \\
\text { stress / } \mathrm{MPa}\end{array}$ & $\begin{array}{l}\text { Corresponding } \\
\text { Strain } / \times 10^{-3}\end{array}$ & $\begin{array}{l}\text { Elastic modulus / } \\
\mathrm{GPa}\end{array}$ & $\begin{array}{l}\text { Corresponding } \\
\text { Stress / } \mathrm{MPa}\end{array}$ & $\begin{array}{l}\text { Corresponding } \\
\text { Strain } / \times 10^{-3}\end{array}$ & $\mathrm{EM} / \mathrm{GPa}$ \\
\hline \multirow{5}{*}{$1-3$} & 1 & 37,07 & 4,61 & 16,10 & 41,81 & 5,02 & 36,97 \\
\hline & 2 & 39,84 & 5,04 & 17,22 & 41,81 & 5,16 & 35,97 \\
\hline & 3 & 37,50 & 5,02 & 18,32 & 41,76 & 5,26 & 36,04 \\
\hline & 4 & 37,50 & 5,08 & 18,63 & 41,80 & 5,33 & 36,52 \\
\hline & 5 & 37,41 & 5,13 & 19,10 & 41,82 & 5,37 & 38,84 \\
\hline \multirow{5}{*}{$3-1$} & 1 & 35,54 & 3,84 & 17,71 & 41,63 & 4,20 & 34,10 \\
\hline & 2 & 35,98 & 4,00 & 21,15 & 41,60 & 4,29 & 32,03 \\
\hline & 3 & 34,60 & 3,99 & 21,55 & 41,61 & 4,34 & 32,53 \\
\hline & 4 & 35,94 & 4,10 & 21,89 & 41,54 & 4,38 & 34,23 \\
\hline & 5 & 35,93 & 4,16 & 21,83 & 41,56 & 4,43 & 35,04 \\
\hline \multirow{5}{*}{$3-2$} & 1 & 34,62 & 4,67 & 15,71 & 41,63 & 5,13 & 34,69 \\
\hline & 2 & 35,57 & 4,86 & 19,86 & 41,58 & 5,19 & 33,49 \\
\hline & 3 & 35,59 & 4,93 & 20,50 & 41,59 & 5,24 & 35,23 \\
\hline & 4 & 36,04 & 4,99 & 20,46 & 41,61 & 5,29 & 36,14 \\
\hline & 5 & 37,30 & 5,01 & 20,55 & 41,60 & 5,33 & 37,88 \\
\hline \multirow{5}{*}{$3-3$} & 1 & 33,49 & 4,58 & 13,01 & 41,60 & 5,49 & 30,39 \\
\hline & 2 & 35,13 & 5,18 & 16,65 & 41,65 & 5,63 & 27,89 \\
\hline & 3 & 35,58 & 5,35 & 16,95 & 41,67 & 5,74 & 27,70 \\
\hline & 4 & 36,52 & 5,49 & 17,15 & 41,60 & 5,83 & 28,93 \\
\hline & 5 & 35,97 & 5,54 & 17,58 & 41,73 & 5,89 & 29,30 \\
\hline \multirow{5}{*}{$4-1$} & 1 & 37,60 & 3,37 & 21,65 & 41,55 & 3,57 & 34,55 \\
\hline & 2 & 36,85 & 3,44 & 24,27 & 41,52 & 3,65 & 34,34 \\
\hline & 3 & 38,99 & 3,59 & 25,29 & 41,54 & 3,70 & 35,54 \\
\hline & 4 & 39,60 & 3,66 & 25,14 & 41,52 & 3,75 & 37,41 \\
\hline & 5 & 37,59 & 3,62 & 25,34 & 41,62 & 3,79 & 38,69 \\
\hline
\end{tabular}

Then, the loading segment and unloading segment of the stress-strain curve under cyclic load were fitted by the same method. The fitting results show how the tangent modulus of each specimen varies in the loading and unloading phases of each load cycle. The peak tangent moduli of each specimen in the loading and unloading segments were taken as the elastic moduli of that specimen.
Then, the stresses and strains at the point of the peak tangent moduli (hereinafter referred to as the corresponding stresses and strains) were obtained. The plastic strain of each specimen in each cycle was also measured. All these data are presented in Tab. 1 below. Note that Tab. 1 only lists the data on qualified specimens. 
As mentioned before, the specimens with obvious defects were discarded after numbering and before the tests.

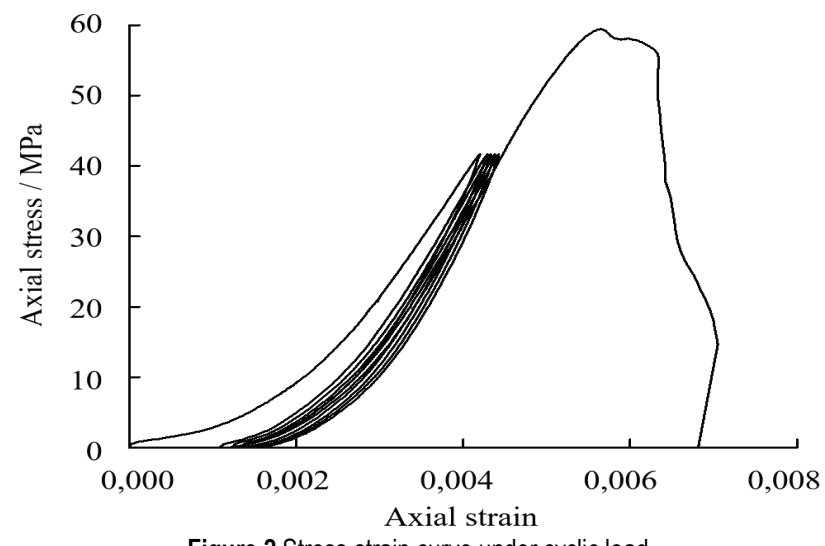

Figure 2 Stress-strain curve under cyclic load

It can be seen from Tab. 1 that the specimens differed in their corresponding strains in the loading phase of the same cycle. For example, this strain of specimen 4-1 increased from 0,00337 in the initial cycle to 0,00362 in the final cycle, while that of specimen 3-3 increased from 0,00458 to 0,00554 . The two specimens had differences in strain level and increment. The differences can be attributed to the following factors: The large blocks from the coalface were already damaged under the disturbance of roadway excavation. Later, the blocks suffered from different degrees of injuries through transport, coring, cutting and polishing. That is why the specimens had differences, despite being collected at once.

It can also be learned that, for the same specimen, the corresponding strain increased with the growing number of cycles. This is because new plastic strain is created in each cycle.

\subsection{Change Law of Elastic Modulus}

Fig. 3 shows the loading curves of a specimen in different cycles. It can be seen that the elastic modulus of the loading phase could be obtained when the stress was about to reach the peak load in the current cycle. For example, in loading curve 1, the tangent modulus gradually increased in the OA segment before slightly decreasing after point a, i.e. the tangent modulus peaked at point a.

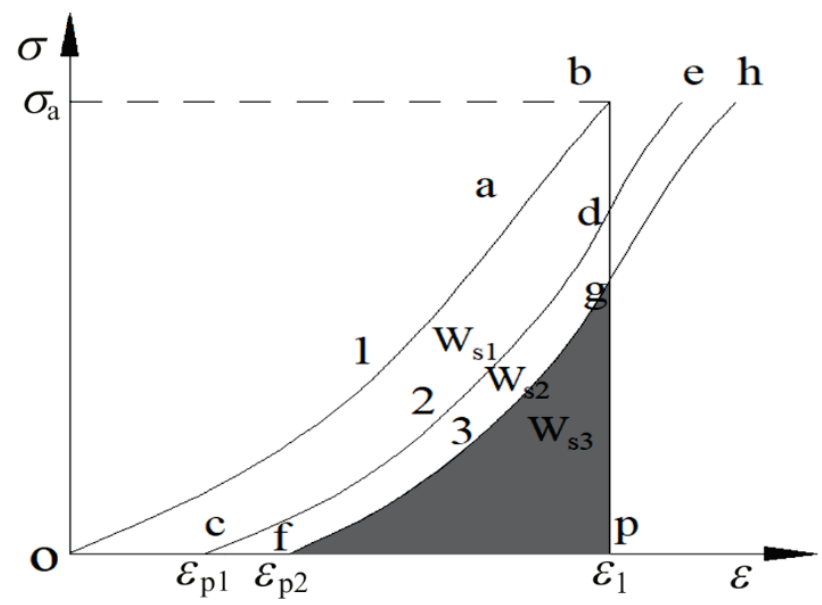

Figure 3 The loading curves of a specimen in different cycles
For the same specimen, the corresponding stresses in different cycles were basically the same. Specimen 4-1 had the highest mean corresponding stress $(38,12 \mathrm{MPa})$ through the five cycles, while Specimen 3-3 had the lowest corresponding stress $(35,34 \mathrm{MPa})$. The mean corresponding stress of Specimen 3-3 stood at 36,55 MPa. Therefore, the specimens from the same type of rock are similar in corresponding stress, although varied in corresponding strain.

For clarity, the relationship between elastic modulus of each specimen with cycle number was plotted (Fig. 4) based on the data in Tab. 1. As shown in Fig. 4, the specimens had some differences in elastic modulus, but the elastic modulus of each specimen increased with cycle number and tended to be stable. Meanwhile, the specimens were all hardened under strain. The most significant increase in elastic modulus was observed in cycle 2 . Taking specimen 3-3 for example, the elastic modulus increased by 3,54 GPa from cycle 1 to cycle 2 , and 4,57 GPa from cycle 1 to cycle 5; however, the elastic modulus increment from cycle 4 to cycle 5 was merely $0,43 \mathrm{GPa}$.

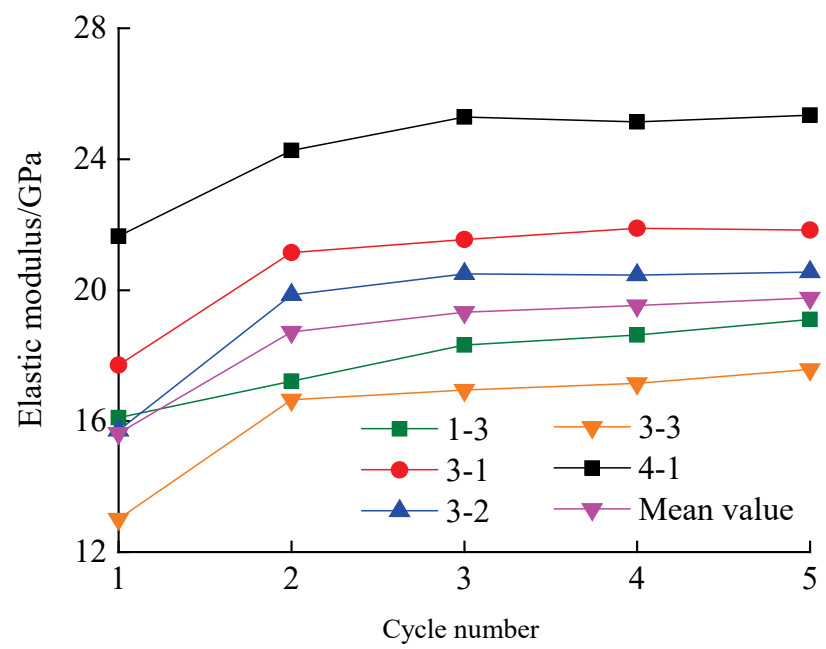

Figure 4 Variation in elastic modulus with cycle number

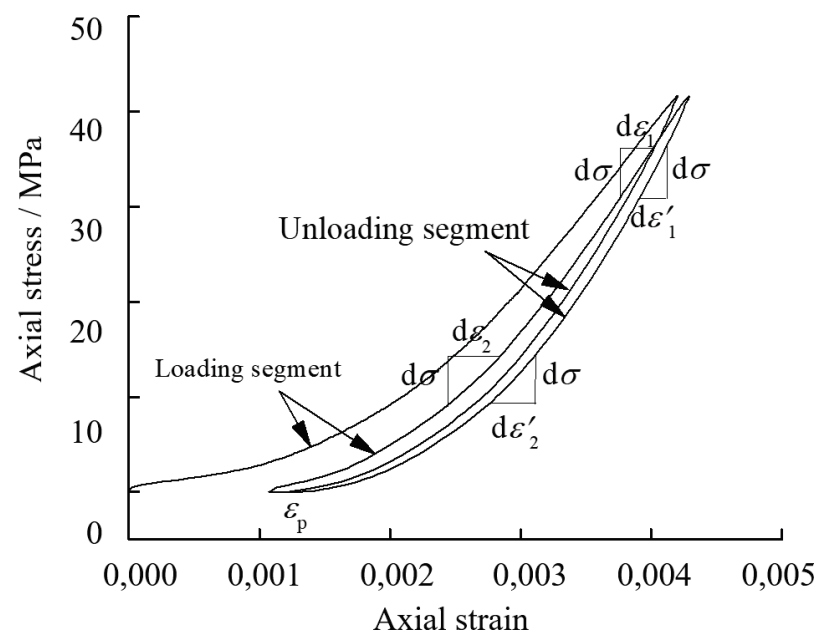

Figure 5 Variation in tangent modulus of loading and unloading phases

On entering the unloading phase, the compacted specimens rebounded slowly with the lifting of the load head. As the load gradually declined, some closed cracks and fissures were reopened. The smaller the load, the more the reopening cracks and the greater the opening. In this 
process, the rock particles and their gaps gradually returned to their original form, and the specimens went through an accelerated process of rebound deformation. Therefore, for the same $\mathrm{d} \sigma, \mathrm{d} \varepsilon_{1}{ }^{\prime}$ must be smaller than $\mathrm{d} \varepsilon_{2}{ }^{\prime}$. Thus, the tangent modulus gradually decreased (Fig. 5). In the same cycle, the tangent modulus of the loading phase was smaller than that of the unloading phase under the same stress, i.e. $\mathrm{d} \varepsilon_{1}>\mathrm{d} \varepsilon_{1}{ }^{\prime}$ and $\mathrm{d} \varepsilon_{2}>\mathrm{d} \varepsilon_{2}{ }^{\prime}$. This is because the strain of the loading phase is smaller than that of the unloading phase in the same cycle. The strain difference between the loading and unloading phases is the plastic strain $\varepsilon_{\mathrm{p}}$ generated in that cycle.

The corresponding stresses and the variation in elastic moduli of different specimens were analyzed below.

Before loading, the sandstone specimens were damaged to different degrees, as evidenced by their differences in the development of cracks and fissures. Therefore, the specimens witnessed different levels of deformation with the growing axial load in the loading phase.

When the load reached a certain level, most cracks and fissures were closed, and the specimens entered the nearelastic phase. From then on, the specimen deformation was mainly caused by the deformation of rock particles and the shrinking gaps between them. With further closure of cracks and fissures, the tangent moduli of the specimens gradually reached the peak values in the loading phase.

In the course of loading, the closure of original cracks occurred at the same time with the generation of new cracks, and the original cracks were closed faster than how the new cracks were generated. When most original cracks and fissures were closed, the number of new cracks and fissures started to grow.

For the above specimens, the elastic moduli were obtained under $36,55 \mathrm{MPa}$. It is extremely difficult for the specimens to deform under this load level. In fact, this load level marks a turning point: more cracks were closed than generated before this point, but more cracks were generated than closed after that (i.e. the specimens were damaged more seriously). With the growing degree of damages, the tangent modulus of each specimen started to decrease until the load reached the preset level.

Our sandstone specimens were unloaded from the level of $40 \mathrm{MPa}$, which brought a limited amount of new damages. In each new cycle, the few uncompressed cracks and fissures in the loading phase of the previous cycle, as well as the cracks and fissures recovered in the unloading phase, were further compressed, pushing up the elastic modulus of each specimen.

New cracks were observed in the loading and unloading phases of all the subsequent cycles. However, the number of new cracks is much smaller than that of the cracks and fissures compacted in the first cycle. Therefore, the elastic modulus of cycle 2 was slightly higher than that of cycle 1 , and similar to that of cycles 3,4 and 5 .

\subsection{Strain Damage Features}

The sandstone specimens were damaged in each cycle. The damage variable $D$ should be introduced to assess the degree of damage. There are many ways to define this variable, such as defining it with the density change, the elastic modulus variation, the cycle number, the number of acoustic emissions or the gap change. The most common method is to measure this variable with the variation in elastic modulus. Of course, this approach needs to be modified properly according to the actual situation.

In our tests, the specimens were unloaded before the peak of the stress-strain curves. As shown in Tab. 1, the elastic moduli of each specimen in the last four cycles were greater than the elastic modulus in the first cycle, indicating that Eq. (1) is not suitable for defining the damage variable $D$ here. Since the specimen damage always increased with the cycle number, the author decided to define the damage variable $D$ from the angle of energy.

The loading and unloading phases are accompanied by the accumulation and release of energy. In Fig. 3, the area between the loading segment of the stress-strain curve and the $\varepsilon$ axis can be defined as the density of input energy $W_{\mathrm{i}}$; meanwhile, the area between the unloading segment of that curve and the $\varepsilon$ axis can be regarded as the density of accumulated energy $W_{\mathrm{s}}$. For the same type of rock, the $W_{\mathrm{s}}$ remains constant when the other conditions (e.g. loading / unloading rate and confining pressure) are the same, and only depends on the damage degree of the specimen. On this basis, the damage variable $D$ can be defined as follows by the $W_{\mathrm{s}}$ of the rock in the loading phase under the same stress.

In Fig. 3, the strain under the loading phase stress of $\sigma_{\mathrm{a}}$ in the first cycle is denoted as $\varepsilon_{1}$. Then, a vertical line to the $\varepsilon$ axis was drawn passing point b. The area between the loading segment, the line bp and the $\varepsilon$ axis represents the accumulated energy $W_{\mathrm{s} i}$ of the specimen in cycle $i$ under the stress of $\varepsilon_{1}$ :

$$
W_{\mathrm{s} i}=\int_{\varepsilon_{\mathrm{p}}^{i-1}}^{\varepsilon_{1}} \sigma_{i} \mathrm{~d} \varepsilon
$$

where $\varepsilon_{\mathrm{p}}^{i-1}$ is the plastic strain of the specimen in the first $i$ -1 cycles $\left(\varepsilon_{\mathrm{p} 0}=0\right) ; \sigma_{i}$ is the stress of cycle $i$. Then, the damage variable $D$ of the sandstone specimen can be defined as:

$$
D=1-\frac{W_{\mathrm{s} i}}{W_{0}}
$$

where $W_{0}$ is the accumulated energy density of intact specimen. Here, the accumulated energy density of the specimen in cycle 1 is taken as $W_{0}$.

Table 2 The damage variables of each specimen in different cycles

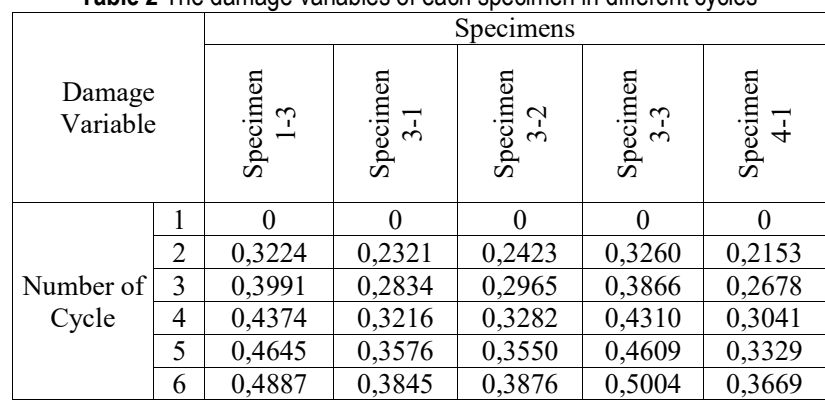

As shown in Fig. 6, the damage variable computed by Eq. (3) of each sandstone specimen increased with cycle 
number. The damage variables of specimens 1-3 and 3-3 changed by similar degrees, and those of the other three specimens also had similar degrees of changes. The first two specimens had greater changes of damage variable than the latter three specimens. The five specimens bore high resemblance in how the damage variable changes: the damages in cycles 1 and 2 were much greater than those in subsequent cycles. A possible reason lies in the fact that the specimens suffered much greater irreversible plastic deformation in the initial cycle than the latter cycles (Tab. $1)$.

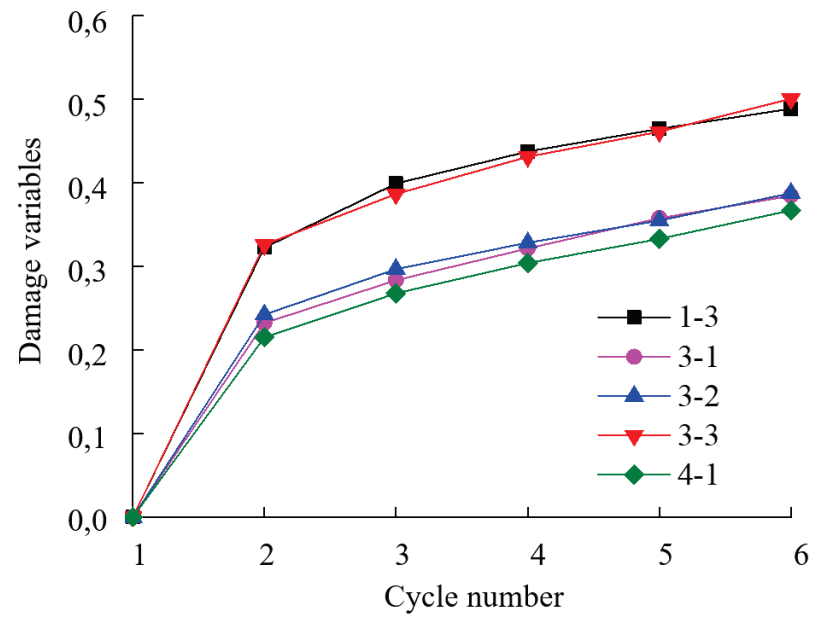

Figure 6 Variation in damage variable of each specimen with cycle number

In fact, the loading phase curves constantly moved right with the growing number of cycles. This rightward motion signifies the generation of plastic strain in each cycle. Thus, the specimens must be damaged.

According to Eq. (3), the damage variable has a direct correlation with $W_{\mathrm{s} i}$. The continuous decrease in $W_{\mathrm{s} i}$ is the combined effect of several factors: (1) plastic strains are generated by the specimens in different cycles; (2) the loading segment of stress-strain curve has shape changes in different cycles; (3) the shape change hinges on the damage degree. Therefore, it is reasonable to use $W_{\mathrm{s} i}$ to capture the variation in specimen damages with cycle number.

Of course, this definition method for the damage variable only reflects the damage degree of a rock specimen in the loading phase of a cycle when the axial strain reaches the fixed level of $\varepsilon_{1}$. The results demonstrate the cumulative damages at a point of the specimen in the loading phase of each cycle, rather than the real-time damage. Despite this, our method can largely reflect the change law of damage degree of the specimen in cyclic loading / unloading.

Fig. 7 shows how the mean damage variable changes with the cycle number. The relationship between the mean damage variable and cycle number can be fitted by $\left(R^{2}=\right.$ 0,999):

$$
D=0,256+0,100 \times \ln (N+0,077)
$$

where $N$ is the number of cycles. It can be seen from Fig. 7 that the damage variables continued to increase in the last few cycles. If this trend continues, the damages will continue to accumulate in a few more cycles, such that the specimen can no longer withstand the level cyclic load but fail.

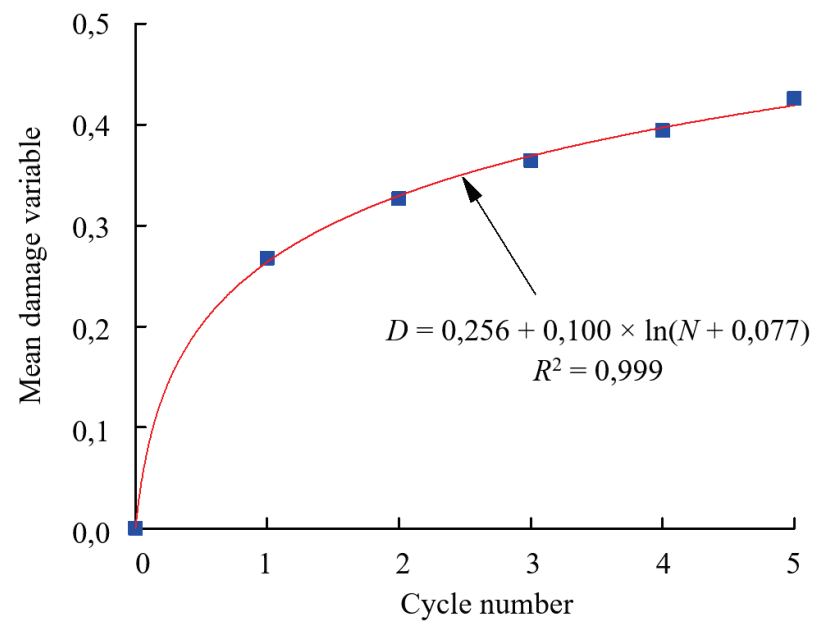

Figure 7 The fitting curve of mean damage variables

\section{CONCLUSION}

(1) For each specimen, the loading segment of the stress-strain curve was fitted. The fitting results show that the tangent modulus must have a peak value in the loading phase. Thus, the peak tangent modulus was taken as the elastic modulus of the specimen. The specimens were similar in corresponding stress, although varied in corresponding strain. In the same cycle, the tangent modulus of the loading phase was smaller than that of the unloading phase under the same stress.

(2) The elastic moduli of rock specimens increased with the growing number of cycles, and tended to be stable. The elastic modulus of cycle 2 was slightly higher than that of cycle 1, and similar to that of cycles 3,4 and 5 . In addition, the specimens were all hardened under strain.

(3) Based on the stress-strain curves, the damage variables of the sandstone specimens under cyclic loading were defined from the angle of energy. This method successfully reflects the accumulation of specimen damages, and correctly fitted the relationship between mean damage variable and cycle number.

Of course, there are several limitations of our research. First, the cyclic load level was set to 2 / 3 of the ultimate strength of sandstone. The test results may vary if the load level is adjusted, such as close to or above the ultimate strength. Second, Fig. 7 shows that the damage variable increases linearly with cycle number, but our tests only cover five load cycles. These limitations will be solved in the future research through loading / unloading tests with more cycles, aiming to disclose features of sandstone deformation and failure and the change law of our damage variable under more load cycles.

\section{EXPECTATION}

(1) The cyclic loading given in this test is about two thirds of the sandstone strength. If changing load amplitude, the different results may be obtained, e.g. making unloading at pre-peak or after-peak of sandstone strength, then to achieve the different conclusions from 
above, therefore, it is necessary to conduct more tests for further study.

(2) Fig. 6 shows that the damage variable increases linearly with number of cycle, but only 5 cycles are used in this paper. Therefore, in future, more cycles can be taken to make loading / unloading test for the test specimen, so as to explore the sandstone deformation failure features in more cycles and re-define the variation rule of damage variable.

\section{Acknowledgements}

This paper is supported by Postgraduate Innovation Fund, Anhui University of Science and Technology (Grant No.: 2017CX2011), Natural Science Foundation of Anhui Province (Grant No.: 1608085QE122), Open Fund of Henan Province Colleges and Universities Deep Mine Construction Key Discipline Open Laboratory (Grant No.: 2015KF-05), and China Postdoctoral Science Foundation (Grant No.: 2016M590558).

\section{REFERENCES}

[1] Xiao, J. Q., Feng, X. T., \& Ding, D. X. (2010). Study of hysteresis and damping effects of rock subjected to constant amplitude cyclic loading. Chinese Journal of Rock Mechanics and Engineering, 29(8), 1677-1683.

[2] Xiao, J. Q., Ding, D. X., \& Xu, G. (2010). Deformation characteristics of rock under constant amplitude cyclic loading. Journal of Central South University (Science and Technology), 41(2), 685-691. https://doi.org/CNKI:SUN:ZNGD.0.2010-02-052

[3] He, M. M., Chen, Y. S., \& Li, N. (2015). Deformation and energy characteristics of sandstone subjected to uniaxial cyclic loading. Journal of China Coal Society, 40(8), 18051812. https://doi.org/CNKI:SUN:MTXB.0.2015-08-014

[4] Xia, D., Yang, T. H., \& Wang, P. T. (2014). Analysis on damage and energy in deformation and fracture of saturated rock subjected to cyclic loading and unloading. Journal of Northeastern University (Natural Science), 35(6), 867-870. https://doi.org/10.3969/j.issn.1005-3026.2014.06.024

[5] Liu, J. F., Xu, J., \& Li, Q. S. (2010). Experimental research on damping parameters of rock under cyclic loading. Chinese Journal of Rock Mechanics and Engineering, 29(5), 1036-1041.

[6] Wang, J. P., Li, Y. S., Zhang, C. (2015). Experimental study on the mechanical behaviour of soft rock under cyclic loading. Science Technology and Engineering, 15(29), 183188.

[7] Cai, M. F., He, M. C., \& Liu, D. Y. (2002). Rock Mechanics and Engineering. Science Press, Beijing,

[8] Wang, J. L. \& Zuo, H. W. (1998). Study on size effect of young's modulus for rock. Rock and Soil Mechanics, 19(1), 60-64.

[9] Wang, L. Q., Tang, H. M., \& Xia, Y. Y. (2008), Study on determination method for elastic modulus of differently weathered rock mass, Metal Mine, 7, 19-21. https://doi.org/10.3321/j.issn:1001-1250.2008.07.006

[10] Jin, C. Y., Li, J., \& Feng, X. T. (2014). The determination method of elastic modulus of deep damage rock mass. Journal of Mining \& Safety Engineering, 31(1), 78-83.

[11] Yan, X. D., Liu, H. Y., \& Xing, C. F. (2015), Variability of elastic modulus in rock under freezing-thawing cycles. Rock and Soil Mechanics, 36(8), 2315-2322. https://doi.org/CNKI:SUN:YTLX.0.2015-08-027

[12] Xia, C. C., Zhou, S. W., \& Hu, Y. S. (2015). Preliminary study on mechanical property of basalt subjected to cyclic uniaxial stress and cyclic temperature. Chinese Journal of Geotechnical Engineering, 37(6), 1016-1024. https://doi.org/10.11779/CJGE201506007

[13] Ge, X. R. \& Lu, Y. F. (1992), Discussion on fatigue failure and irreversible deformation of rock under cyclic loading. Chinese Journal of Geotechnical Engineering, 14(3), 56-60. https://doi.org/10.1007/BF02943552

[14] Wang, Z. C., Zhao, J. G., \& Li, S. C. (2012). Fatigue mechanical behavior of granite subjected to cyclic load and its constitutive model. Chinese Journal of Rock Mechanics and Engineering, 31(9), 1888-1900. https://doi.org/CNKI:SUN:YSLX.0.2012-09-018

[15] Lemaitre, J, (1996). A course on damage mechanics. Springer-Verlag, Berlin. https://doi.org/10.1007/978-3-642-18255-6

[16] Ju, Y. \& Xie, H. P. (1998). A variable condition of the damage description based on hypothesis of strain equivalence. Chinese Journal of applied mechanics, 15(1), 43-49. https://doi.org/10.1088/0256-307X/16/12/001

[17] Xie, H. P., Ju, Y., \& Dong, Y. L. (1997). Discuss on elastic modulus method of classical damage definition. Mechanics in Engineering, 19(2), 1-5. https://doi.org/10.1088/10.6052/1000-0992-1999-405

[18] Liu, J. F., Pei, J. L., \& Zhang, R. (2012). Discussion on damage modulus for rock based on multi-level load test. Chinese Journal of Rock Mechanics and Engineering, 31(S1), 3145-3151. https://doi.org/10.3969/j.issn.1000-6915.2012.z1.074

[19] Liu, J. F., Xu, J., \& Pei, J. L. (2011). Research on unloading modulus for salt rock damage testing. Journal of Sichuan University (Engineering Science Edition), 43(4), 57-62. https://doi.org/10.1088/0253-6102/55/2/31

[20] Zhou, J. W., Yang, X. G., \& Fu, W. X. (2010). Experimental test and fracture damage mechanical characteristics of brittle rock under uniaxial cyclic loading and unloading conditions. Chinese Journal of Rock Mechanics and Engineering, 29(6), 1172-1183.

[21] Xu, T., Ren, S. Y., \& Fan, C. (2017). Determination of rock creep damage curve based on Norton equation. Journal of Water Resources and Architectural Engineering, 15(2), 3742. https://doi.org/10,3969/j.issn.1672-1144.2017.02.007

[22] Fan, H. L. \& Jin, F. N. (2000). Effective modulus method in damage mechanics of rock. Chinese Journal of Rock Mechanics and Engineering, 19(4), 432-435. https://doi.org/10.3321/j.issn:1000-6915.2000.04.008

[23] Zhao, C., Wu, K., \& Li, S. C. (2013). Energy characteristics and damage deformation of rock subjected to cyclic loading. Chinese Journal of Geotechnical Engineering, 35(5), 890896.

[24] Xie, H. P., Ju, Y., \& Li, L. Y. (2008). Energy mechanism of deformation and failure of rock masses. Chinese Journal of Rock Mechanics and Engineering, 27(9), 1729-1740. https://doi.org/CNKI:SUN:YSLX.0.2008-09-003

[25] Zhang, Z. Z. (2013), Energy evolution mechanism during rock deformation and failure. China University of Mining and Technology press, Xuzhou. 


\section{Contact information:}

Chengjie LI, PhD candidate

School of Civil and Architectural Engineering,

Anhui University of Science and Technology,

232001 Huainan, China

E-mail:651832861@qq.com

Peijie LOU, lecturer

(Corresponding author)

1) School of Civil and Architectural Engineering,

Anhui University of Science and Technology, 232001 Huainan, China,

2) Opening Laboratory for Deep Mine Construction,

Henan Polytechnic University, 454000 Jiaozuo, China,

3) Center for Post-Doctoral Studies of Civil Engineering,

Anhui University of Science and Technology, 232001 Huainan, China,

4) Engineering Research Center of Underground Mine Construction,

Ministry of Education, Anhui University of Science and Technology,

232001 Huainan, China

E-mail: 470474720@qq.com

Shuling Liang, assistant experimentalist

School of Civil and Architectural Engineering,

Anhui University of Science and Technology,

232001 Huainan, China

E-mail: 764257884@qq.com

Mingming FENG, master degree candidate

School of Civil and Architectural Engineering,

Anhui University of Science and Technology,

232001 Huainan, China

E-mail: 1269938652@qq.com

Bin PAN, master degree candidate

School of Civil and Architectural Engineering,

Anhui University of Science and Technology,

232001 Huainan, China

E-mail: 2529863406@qq.com 